\title{
RESOLUÇÃO DE PROBLEMAS INTERPESSOAIS: PROMOVENDO O DESENVOLVIMENTO SOCIOCOGNITIVO NA ESCOLA
}

\author{
Marisa Cosenza Rodrigues* \\ Jaqueline Pereira Dias ${ }^{\#}$ \\ Márcia de Fátima Rabello Lovisi de Freitas
}

\begin{abstract}
RESUMO. O presente trabalho relata uma pesquisa-intervenção que objetivou implementar e avaliar o impacto de um programa adaptado, já existente na literatura, em Habilidades de Resolução de Problemas Interpessoais. Participaram 30 crianças de 6 e 7 anos do $1^{\circ}$ ano do Ensino Fundamental de uma escola pública de Minas Gerais. O estudo envolveu pré e pós-avaliação com a utilização do instrumento SSRS-BR e observações não sistemáticas realizadas pelas pesquisadoras e professoras. De forma complementar, foram realizadas reuniões e orientações aos responsáveis e professoras das crianças. Os resultados comparativos da pré e pós-avaliação das crianças indicam um incremento de algumas habilidades, como empatia, assertividade, expressão de sentimento positivo, civilidade e responsabilidade, concordando com os dados das observações realizadas. Observou-se maior sensibilização por parte dos pais e professores quanto às estratégias educativas e manejo de comportamentos indesejáveis. Foi possível constatar, também, uma maior abertura quanto às práticas preventivas da psicologia escolar no contexto educativo.
\end{abstract}

Palavras-chave: Resolução de problemas interpessoais; desenvolvimento sociocognitivo; promoção de saúde.

\section{INTERPERSONAL PROBLEM-SOLVING}

\begin{abstract}
The present work reports a research intervention that aimed to implement and evaluate the impact of an adapted program existing in literature about Interpersonal Problem-Solving Skills. Participants included 30 children aged between 6 and 7 years old in the first grade of elementary school. All students were from a public school from Minas Gerais state. The study involved pre-and postassessment using the instrument SSRS-BR and non-systematic observations carried out by researchers and teachers. Additionally, the researchers held meetings and guidance to care providers and teachers of the children. The comparative results of pre-and post-assessment indicated an increase of some skills in children as empathy, assertiveness, expression of positive feeling, civility and responsibility, converging with the data from comments made. There was greater awareness among parents and teachers about the educational strategies and management of undesirable behaviors. It was also found a greater opening regarding preventive practices of school psychology in the educational settings.
\end{abstract}

Key words: Interpersonal problem-solving; social-cognitive development; healthy promotion.

\section{RESOLUCIÓN DE PROBLEMAS INTERPERSONALES: PROMOVER DESARROLLO SOCIOCOGNITIVO EN LA ESCUELA}

\begin{abstract}
RESUMEN. Este trabajo describe una investigación de intervención que tuvo como objetivo implementar y evaluar el impacto de un programa adaptado, existente en la literatura, sobre las Habilidades de Resolución de Problemas Interpersonales. Participaron 30 niños de entre 6 y 7 años del primero año educativo, en una escuela pública de Minas Gerais. El estudio fue realizado por pre-y post-evaluación utilizando el instrumento SSRS-BR y por observaciones no sistemáticas realizadas por los investigadores y profesores. Como complemento, se celebraron reuniones y orientación a los padres y maestros. Los resultados indican un crecimiento de algunas habilidades como empatía, asertividad, expresión de sentimiento positivo, civismo y responsabilidad, en convergencia con los datos de observaciones realizadas. Observó una mayor conciencia por los padres y maestros acerca de estrategias educativas y gestión de comportamientos indeseables. Se encontró también una mayor apertura en las prácticas de prevención de la psicología escolar en el contexto educativo.
\end{abstract}

Palabras-clave: Resolución de problemas interpersonales; desarrollo socio cognitivo; promoción de la salud.

\footnotetext{
Doutora em Psicologia pela PUC de Campinas. Professora Doutora do departamento de Psicologia da Universidade Federal de Juiz de Fora.

\# Graduanda em Psicologia pela Universidade Federal de Juiz de Fora.
} 
A escola, por integrar pessoas e interesses distintos, tem se tornado um lócus de ocorrência de conflitos interpessoais, mas se constitui, por outro lado, em uma instância legítima de educação para a cidadania e para atitudes e práticas de não violência (Loos \& Zeller, 2007; Chrispino, 2007). Del Prette e Del Prette (2003) salientam que a experiência escolar é central para as aquisições sociais e educacionais das crianças em nossa cultura. Tais experiências podem canalizar diferentes trajetórias em direção à vida adulta, tendo-se em vista as principais tarefas evolutivas desse período, como competência nas relações interpessoais, o progresso na escolarização, a adesão às regras da sociedade para conduta prossocial e uma imagem positiva de si mesmo. Nesse sentido, Rodrigues (2005) sugere que a escola deve funcionar como fator de proteção ${ }^{1}$, pois pode favorecer a evolução de estágios cognitivos da criança, diversificando seu repertório comportamental, fortalecendo suas habilidades/capacidades de enfrentamento das adversidades e incentivando soluções criativas para seus problemas.

Sabe-se que a agressividade infantil, mesmo sem estatísticas rigorosamente definidas, tem atingido altos níveis em todo o mundo, inclusive no Brasil (Baraldi \& Silvares, 2003). Os comportamentos indesejáveis, como a conduta agressiva e a violação de regras, desenvolvem-se desde a primeira infância. São aprendidos, inicialmente, no ambiente familiar e podem ser potencializados pela inserção na escola, que funcionaria também como fator de risco ${ }^{2}$ para essas crianças (Webster-Stratton, Reid \& Hammond, 2001). Nesta perspectiva, muitos autores (como Loos \& Zeller, 2007; Kazdin, Siegel \& Bass, 1992; Webster-Stratton, Reid \& Hammond, 2004) ressaltam que os esquemas de interação social que se organizam para a solução de problemas durante a infância teriam maior probabilidade de ser, também, de natureza mais violenta. Del Prette e Del Prette (2005) e Vasconcellos, Picon, Prochnow e Gaue (2006) salientam que a agressividade infantil relaciona-se a um padrão sociocognitivo que inclui processamento distorcido de informações sociais, repertório limitado de alternativas para a resolução de problemas, déficits de desempenhos sociais e falta de habilidade

1 Fatores de proteção podem ser considerados como influências positivas ao desenvolvimento, que atuam como precursores de respostas adaptativas (Poletto \& Koller, 2006).

2 Fatores de risco estão relacionados a situações negativas que aumentam a probabilidade de o indivíduo desenvolver problemas sociais, físicos e psicológicos (Poletto \& Koller, 2006). empática, ou seja, dificuldade de inferir sobre as emoções e intenções alheias.

Como observa Rodrigues (2005), durante a infância, as crianças estão particularmente flexíveis e sensíveis à estimulação, o que influencia diretamente as etapas posteriores do desenvolvimento. A referida autora, assim como López (2008), defende que intervenções preventivas e proativas devem constituir um dos focos de trabalho do psicólogo nos contextos educativos. As estratégias de prevenção primária ${ }^{3}$ beneficiam toda a população escolar, promovendo o desenvolvimento de habilidades por meio de um modelo construtor de competências (Shure \& Spivack, 1982; Shure \& Healey, 1993) e com baixos custos econômicos para a população atendida.

A Organização Mundial de Saúde (WHO, 1999) postula que práticas preventivas devem fazer integrar plena e continuamente o currículo escolar, não apenas como tema transversal. Neste contexto, estabelece o ensino das habilidades sociais como prevenção primária do uso de drogas, da gravidez na adolescência e da violência, bem como para a prevenção da AIDS, promoção da autoestima e da autoconfiança. O documento ressalta, ainda, que o ensino destas habilidades deveria ser colocado à disposição de todas as crianças e adolescentes nas escolas. Assim, torna-se necessário tecer considerações acerca da importância das habilidades sociais para o desenvolvimento infantil e o papel promotor da escola e da família.

\section{HABILIDADES SOCIAIS}

As habilidades sociais são consideradas aprendizagens importantes ao repertório comportamental de crianças pequenas. Del Prette e Del Prette (2005) apontam que a expressão habilidades sociais refere-se a diferentes categorias do repertório comportamental social de um sujeito, contribuindo para sua competência social, o que favorece uma relação satisfatória e produtiva com as demais pessoas. Embora não haja consenso acerca da definição de competência social (Bolsoni-Silva et al., 2006), este conceito é definido como a capacidade de

O conceito de prevenção primária implica em uma intervenção com o objetivo intencional de reduzir a ocorrência de problemas de ajustamento em indivíduos normais no futuro, além de promover o funcionamento mental saudável e o desenvolvimento de habilidades especificas que propiciem a qualidade de vida e o bemestar. Tal intervenção, quando se volta para uma população ampla é denominada de estratégia universal (Durlak \& Wells, 1997). 
articular emoções, pensamentos e comportamentos em relação a metas pessoais e circunstanciais, de forma que gerem consequências satisfatórias para o sujeito e sua relação com outras pessoas (Del Prette \& Del Prette, 2005). Como as habilidades sociais na infância constituem a base da competência social, as crianças que têm oportunidade de aprender e desenvolver suas habilidades sociais tendem a exibir melhor ajustamento social e maior satisfação nas relações interpessoais, além de prevenir o desenvolvimento de condutas antissociais ou de isolamento social na adolescência e na vida adulta (López, 2008).

Del Prette e Del Prette (2005) salientam também que a competência social na infância pode ser considerada como um dos fatores de proteção para uma trajetória desenvolvimental satisfatória. De acordo com Baraldi e Silvares (2003), a aquisição de habilidades sociais na infância pode ser vista com uma das formas diretas de impedir ou controlar o comportamento agressivo e, indiretamente, um meio de prevenir o risco de rejeição por pares a que as crianças agressivas estão submetidas.

A literatura indica que as crianças com déficits em habilidades sociais e na autorregulação emocional tendem a conduzir rapidamente pais, professores e pares a interações coercitivas. Como apontado em diversos estudos na área (Dessen, Polonia, 2007; Baraldi, Silvares, 2003; Webster-Stratton, Reid \& Hammond, 2004), as práticas de ação ineficientes dos pais são vistas como determinantes do problema de comportamento da criança. Dessa forma, uma intervenção preventiva deve abranger as práticas educativas parentais, o comportamento da criança e sua relação com os pares e professores, uma vez que estes sistemas se retroalimentam.

O estudo meta-analítico de Durlak e Wells (1997) indica que programas de prevenção primária em saúde mental vêm apresentando resultados positivos, no plano internacional, desde a década de 80. Os autores destacam estudos envolvendo programas preventivos voltados para a área interpessoal das habilidades sociais. Tais estudos, que têm como marco inicial os estudos pioneiros em crianças pré-escolares de Shure e Spivack (1982), privilegiam a solução cognitiva de problemas interpessoais.

Shure e Spivack (1982) elaboraram uma abordagem geral de solução de problemas interpessoais com destaque teórico para o funcionamento pessoal saudável de crianças. Tais autores ressaltam que os programas com enfoque na resolução de problemas interpessoais visam: a) prevenir disfunções e promover saúde e b) reduzir a incidência de comportamentos interpessoais e emocionais indesejáveis ou mal-ajustados socialmente.

Dando continuidade a seus estudos, Shure apresenta em 1992 seu trabalho I Can Problem Solve (Shure, 2006). As habilidades de resolução de problemas interpessoais, foco do presente estudo, apresentam-se como uma das classes das habilidades sociais que podem ser promovidas em crianças. Por constituir uma estratégia preventiva e promotora da saúde psicossocial infantil, e nesse sentido, um potencial fator de proteção ao desenvolvimento da criança, o tema torna-se foco de interesse tanto para pesquisadores quanto para profissionais das áreas de psicologia e educação.

\section{HABILIDADES DE RESOLUÇÃO DE PROBLEMAS INTERPESSOAIS}

A resolução de problemas interpessoais é entendida como um processo atitudinal complexo, envolvendo aspectos comportamentais, cognitivos e afetivos (Leme, 2004). Del Prette e Del Prette (2005) a definem como um processo metacognitivo que leva a pessoa a reconhecer seus próprios sentimentos e pensamentos, para depois modificar seu comportamento subsequente.

Um problema interpessoal também pode ser definido como um conflito. De acordo com Chrispino (2007), entende-se por conflito qualquer opinião diferente ou uma maneira alternativa de interpretar ou ver algum acontecimento. O conflito é uma manifestação natural e possui algumas vantagens, como a regulação das relações sociais, desenvolvimento da empatia e reconhecimento das diferenças, o que possibilita a oportunidade de crescimento e de amadurecimento social.

Autores como Leme (2004), Loos, Zeller (2007) e Borges e Marturano (2009) salientam que há várias maneiras de se resolver um conflito. Uma delas é a prática de comportamentos coercitivos, como o agressivo, que não levam em consideração os direitos, sentimentos e opiniões dos outros, valendo-se apenas de suas próprias opiniões. Outra maneira de resolução é o comportamento submisso, contrário ao agressivo, que considera os direitos e sentimentos do outro, mas não os seus. A maneira mais desejada e evoluída do ponto de vista sociocognitivo é o comportamento assertivo, no qual a pessoa explicita seus próprios direitos, sentimentos e ideias sem ferir a opinião do outro. Tais tendências são aprendidas por meio de modelos, como os professores e pais/responsáveis (Kazdin, Siegel, Bass, 1992; Dessen \& Polonia, 2007). 
As habilidades de resolução de problemas interpessoais promovem uma tomada de decisão de forma cautelosa e reflexiva, pois facilitam a análise das consequências de cada comportamento emitido e permitem a escolha e implementação da alternativa mais adequada ao conflito, evitando a emissão de respostas agressivas (Shure \& Spivack, 1982; Borges \& Marturano, 2009). Essas habilidades, após serem aprendidas, tendem a levar a criança a enfrentar um problema de modo mais adaptativo e saudável. As soluções pensadas pela criança devem fazer parte de sua possibilidade e capacidade de ação, reduzindo as frustrações, a ansiedade e formulando expectativas reais sobre o comportamento do outro.

O programa de resolução de problemas interpessoais de Shure, denominado EPRP, ensina às crianças habilidades de pensar sobre os problemas e sobre o agir interpessoal, e não o que pensar e/ou o que fazer (Shure, 2006). Shure e Spivack (1982) apontam que as habilidades de resolução de problemas interpessoais podem ser identificadas em fases evolutivas a partir dos quatro anos de idade. As intervenções com este foco procuram abordar com a criança a escuta e a observação dos outros, na perspectiva de aprendizagem e conscientização de sentimentos e pensamentos, além do entendimento de que suas ações têm consequências.

Há diversos estudos na área das Habilidades de Resolução de Problemas Interpessoais (HRPI). Alguns relacionam tais habilidades com o comportamento inibido ou impulsivo (Elias, Marturano, 2004; Borges, Marturano, 2002; Borges, Marturano, 2009; Shure \& Spivack, 1982), outros com dificuldades de aprendizagem (Elias, Marturano, Motta \& Giurlani, 2003) e outros ainda com grupos específicos de transtornos psicológicos (Anderson, Goddard \& Powell, 2009). Estas pesquisas, apesar de apresentarem metodologias diversificadas, evidenciam resultados satisfatórios, indicando o aprimoramento das HRPI. Como o foco do presente trabalho situa-se na relação entre problemas de socialização e HRPI, será dada maior ênfase ao primeiro tipo de estudos citado acima.

Elias e Marturano (2004) realizaram uma intervenção em um grupo de crianças que apresentavam dificuldades socioemocionais em nível clínico e baixo rendimento escolar, encaminhadas a uma clínica de psicologia. A intervenção foi baseada no programa de Shure (2006). Os resultados obtidos apontaram para a eficácia do programa no que tange à promoção ou aprimoramento das HRPIs, além de ganho no desempenho escolar e minimização de problemas de comportamento.
Em outro estudo, realizado em contexto escolar, Borges e Marturano (2002) realizaram uma pesquisaintervenção em sala de aula, com o intuito de promover HRPIs em crianças do ensino fundamental a partir do programa já mencionado de Shure (2006). Os resultados encontrados mostraram-se satisfatórios, pois crianças que se envolviam em conflitos tiveram sua participação diminuída em ocorrências deste tipo ao longo do programa. Após este estudo inicial, as autoras deram continuidade à proposta ampliando o objetivo para um programa multimodal, incluindo também valores humanos e autocontrole emocional (Borges \& Marturano, 2009). Os resultados indicaram efeitos positivos, pois as crianças diminuíram sua participação em conflitos interpessoais e melhoraram o seu desempenho pró-social, favorecendo o convívio em sala de aula.

$\mathrm{Na}$ perspectiva dos estudos acima referidos, o presente trabalho, realizado em contexto escolar, teve como objetivo favorecer o relacionamento interpessoal e contribuir para um desenvolvimento socioemocional mais saudável a partir da implementação de um programa de HRPI.

\section{MÉTODO}

\section{Participantes}

Os participantes constituíram-se de crianças que cursavam o $1^{\circ}$ ano do Ensino Fundamental de uma escola da rede pública municipal de uma cidade da Zona da Mata mineira. A escola absorve a demanda de alunos provenientes da comunidade local, caracterizando um grupo razoavelmente homogêneo quanto às características socioeconômicas e ao contexto cultural. A instituição solicitou, à época, uma intervenção voltada para a minimização de problemas e conflitos interpessoais para as duas turmas de $1^{\circ}$ ano do turno da tarde. Foram participantes 50 crianças de 6 e 7 anos das turmas referidas; porém somente 30 crianças compuseram a amostra, pois o critério de inclusão foi a entrega do termo de consentimento (TCLE). Dos 30 participantes, $16(53,3 \%)$ eram meninos e 14 (46,7\%), meninas. A idade variou, na pré-avaliação, de 74 a 86 meses, com média aproximada de 80 meses e desvio padrão de $3,8(\mathrm{dp})$. Os demais alunos, sem consentimento ético para a realização do estudo, participaram apenas do programa de intervenção, já que este está incluído no currículo da escola durante o segundo semestre do ano em questão e foi realizado em horário regular, dentro da sala de aula. A amostra distribuiu-se entre duas turmas, ficando 15 crianças na turma A e 15 crianças 
na turma B. Os professores das duas turmas eram diferentes e permaneceram como responsáveis por cada sala durante toda a intervenção. Não foi encontrada diferença estatística entre as turmas com relação à proporção entre meninos e meninas, bem como em relação à média dos postos das idades.

\section{Instrumentos}

Cientes da falta de um instrumento específico para a avaliação das habilidades de resolução de problemas interpessoais validado para o Brasil, optouse por utilizar a Escala de Habilidades Sociais de Estudantes do Ensino Fundamental (SSRS-BR), traduzida por Bandeira, Del Prette, Del Prette e Magalhães (2009) do original SSRS (Social Skills Rating System). A escolha da referida escala deu-se pela necessidade de um parâmetro quantitativo que avaliasse minimamente as habilidades prévias contempladas no programa de intervenção. O SSRSBR é constituído por três questionários de avaliação, respondidos por estudantes, pais e professores, de forma a englobar uma avaliação multimodal das habilidades sociais. Não obstante, como o objetivo do presente estudo não foi avaliar as habilidades sociais como um todo, e sim, algumas de suas classes trabalhadas durante a intervenção, de acordo com a percepção da própria criança, decidiu-se utilizar apenas o questionário de autoavaliação respondido pelos estudantes. Considerando-se que a aplicação de uma escala em crianças pequenas apresenta alto índice de respostas inconsistentes, optou-se por respaldar os resultados em observações comportamentais realizadas pelas professoras das turmas citadas e pelas pesquisadoras, que também eram estagiárias de psicologia escolar da instituição. As observações qualitativas podem constituir recursos complementares aos resultados quantitativos, porquanto possibilitam a compreensão do processo de desenvolvimento.

A escala de autoavaliação é constituída de 34 questões, que são respondidas em termos da frequência da ocorrência de cada comportamento indicado, com três alternativas de respostas: $(0)$ nunca, (1) algumas vezes, (2) muito frequente. Engloba seis fatores avaliativos: responsabilidade, empatia, assertividade, autocontrole, civilidade e expressão de sentimento positivo.

$\mathrm{Na}$ intervenção, foi utilizado o programa desenvolvido por Shure "I Can Problem Solve (ICPS)", traduzido e adaptado para o Brasil com o nome de "Eu Posso Resolver Problemas (EPRP)" (Shure, 2006). O programa caracteriza-se por 83 lições, inicialmente desenvolvidas para serem aplicadas em sala de aula. As lições são divididas em habilidades prévias para resolução de problemas (lições iniciais) e habilidades para resolução de problemas (lições finais). Os objetivos das lições iniciais são: reconhecer e identificar sentimentos em si e nos outros, prestar atenção, considerar o ponto de vista dos outros e aprender a sequenciar eventos. As lições finais objetivam levar a criança a pensar em soluções alternativas para um mesmo problema, bem como avaliar as consequências de suas ações, sentimentos e a decisão pela melhor solução. Outros materiais e recursos utilizados durante a intervenção foram fantoches, ilustrações, livros de histórias infantis, jogos lúdicos e dramatizações.

\section{Procedimentos}

A intervenção iniciou-se após crivo do comitê de ética em pesquisas (CAAE - 1797.0.000.180-08) e consentimento dos responsáveis pela escola. Num primeiro momento, as 30 crianças que compuseram a amostra foram pré-avaliadas quanto ao seu repertório de habilidades sociais, por meio da escala SSRS-BR (Bandeira, Del Prette, Del Prette \& Magalhães, 2009). Estas crianças foram subdivididas em cinco grupos de seis participantes cada, para que as duas pesquisadoras pudessem acompanhar de forma mais cuidadosa o preenchimento das respostas, minimizando assim dificuldades durante o processo de avaliação.

Implementou-se a seguir o programa adaptado em encontros semanais de uma hora de duração, que totalizaram 15 semanas, contando com a participação das crianças e com a presença do professor, para que este pudesse ter a oportunidade de aprimorar estratégias de manejo dos conflitos em sala de aula.

Foram selecionadas 34 lições do livro com o intuito de reduzir o tempo de execução do programa, de maneira que se adequasse ao planejamento pedagógico da escola e à faixa etária das crianças. Os conceitos necessários para o desenvolvimento do programa foram revisados por meio de uma única lição (lição 14), pois as crianças já se mostraram familiarizadas com a maior parte deles. Iniciou-se o trabalho a partir da lição 15 , adequando-se ao recomendado pela autora para crianças que já possuem domínio dos conceitos iniciais. Foram selecionadas 16 lições dentre aquelas que trabalham habilidades prévias para a resolução de problemas e 17 lições para trabalhar as habilidades de resolução de problemas. Ao término do programa os participantes foram submetidos a uma pós-avaliação, seguindo-se os mesmos procedimentos da pré-avaliação já descritos.

De forma complementar à intervenção com as crianças, foram realizadas, simultaneamente, quatro reuniões de pais/responsáveis, uma vez por mês, com 
o objetivo de sensibilizá-los e conscientizá-los para estratégias educativas mais eficazes, estimulando a prática educativa de monitoramento positivo. Os temas discutidos nestes encontros permearam o papel ativo dos pais na educação das crianças, o desenvolvimento infantil saudável, a importância de estabelecer limites e regras para o desenvolvimento psicológico e a promoção da autoestima infantil. Os encontros tiveram, em média, 50 minutos de duração. Foi utilizado um texto-base para dar seguimento às reuniões e, ao final de cada uma delas, era entregue um texto-reflexão, contendo estratégias práticas relacionadas à temática discutida visando favorecer a integração família-escola.

\section{ANÁLISE DOS DADOS}

Após conferências das respostas da escala, os dados do SSRS-BR foram digitados e organizados em um banco de dados. Inicialmente, realizaram-se análises descritivas dos dados. Para a avaliação da intervenção, optou-se por focalizar os itens dos fatores, pois, como já foi dito, nem todos os itens que os formavam representavam aspectos trabalhados na intervenção. Desta forma, a análise de cada item poderia detalhar melhor a mudança de comportamentos específicos. Para a análise dos itens, foi utilizado o teste do Qui-Quadrado de Pearson. Quando violadas as propriedades deste teste, utilizouse a correção do teste exato de Fisher. Para a rejeição da hipótese nula, adotou-se o intervalo de confiança de 95\% ( $\mathrm{p} \leq 0,05)($ Levin, 1987).

\section{RESULTADOS}

Dos 34 itens ou questões que compõem a escala SSRS-BR, 14 itens foram trabalhados diretamente pelas lições do programa de intervenção, 11 foram trabalhados indiretamente e 9 itens não foram trabalhados. Consideraram-se como itens trabalhados diretamente aqueles que tiveram lições específicas do livro voltadas para o seu aprimoramento. Os itens trabalhados de forma indireta aparecem durante a intervenção como tema transversal, sem lições específicas que os promovam.

A partir das análises estatísticas, foi possível encontrar seis itens da escala que apresentaram diferença estatisticamente significativa no teste exato de Fisher entre a pré e a pós-avaliação.

Tabela 1. Análise da Frequência de Respostas aos Itens do SSRS-BR (pré e pós-avaliação):

\begin{tabular}{|c|c|c|c|c|c|c|c|c|}
\hline \multirow{2}{*}{ Itens } & \multirow{2}{*}{ Avaliação } & \multicolumn{2}{|c|}{ Nunca } & \multicolumn{2}{|c|}{ Algumas vezes } & \multicolumn{2}{|c|}{ Muito Frequente } & \multirow{2}{*}{$\frac{\text { Qui Quadrado }}{\text { Valor } p^{*}}$} \\
\hline & & $\mathbf{n}$ & $\%$ & n & $\%$ & $\mathbf{n}$ & $\%$ & \\
\hline Item 6 - Eu digo para os outros quando & Pré & 2 & 6,7 & 8 & 26,7 & 20 & 66,7 & \\
\hline estou chateado com eles $* *$ & Pós & 7 & 23,3 & 10 & 33,3 & 13 & 43,3 & $p=0,029$ \\
\hline Fator Assertividade & Pré & 4 & 13,3 & 12 & 40,0 & 14 & 46,7 & \\
\hline $\begin{array}{l}\text { Item } 7-\text { Eu discordo de adultos sem briga } \\
\text { ou discussão*** }\end{array}$ & Pós & 3 & 10,0 & 4 & 13,3 & 23 & 76,7 & $p=0,050$ \\
\hline Fator Expressão de Sentimento Positivo & Pré & 3 & 10,0 & 7 & 23,3 & 20 & 66,7 & \\
\hline $\begin{array}{l}\text { Item } 16 \text { - Eu demonstro que gosto de } \\
\text { elogios e cumprimentos de amigos }\end{array}$ & Pós & 5 & 16,7 & 3 & 10,0 & 22 & 73,3 & $p=0,016$ \\
\hline Item 20 - Eu digo coisas boas para os & Pré & 4 & 13,3 & 7 & 23,3 & 19 & 63,3 & \\
\hline $\begin{array}{l}\text { outros quando eles fazem alguma coisa } \\
\text { bem feita }\end{array}$ & Pós & 5 & 16,7 & 7 & 23,3 & 18 & 60,0 & $p=0,035$ \\
\hline Fator Responsabilidade Item 25 - Eu sigo & Pré & 1 & 3,3 & 4 & 13,3 & 25 & 83,3 & $0 \Omega 3$ \\
\hline as instruções da professora ou professor & Pós & 1 & 3,3 & 3 & 10,0 & 26 & 86,7 & $=0,003$ \\
\hline Fator Civilidade & Pré & 2 & 6,7 & 3 & 43,3 & 15 & 50,0 & \\
\hline $\begin{array}{l}\text { Item } 31 \text { - Eu peço a meus colegas para } \\
\text { entrar na brincadeira ou no jogo }\end{array}$ & Pós & 5 & 16,7 & 4 & 13,3 & 21 & 70,0 & $p=0,015$ \\
\hline
\end{tabular}

\footnotetext{
* Significativo para $\mathrm{p} \leq 0,05$ no teste do Qui-Quadrado de Pearson com correção do teste exato de Fisher.

** Item não pertencente a nenhum fator.

*** Item presente também no fator Civilidade.
}

Como evidencia a tabela 1 , dos seis itens que apresentaram significância com de nível de $p \leq 0,05$, três foram trabalhados diretamente (itens 6, 7 e 25) e outros três, indiretamente (itens 16, 20 e 31). Ambas as categorias estão incluídas em lições do livro que buscam desenvolver as habilidades prévias para resolução de problemas. Os itens trabalhados diretamente se pautaram em habilidades como empatia, assertividade e prestar atenção. Os outros três itens trabalhados indiretamente demonstram capacidade assertiva e maior iniciativa da criança. A análise dos itens 6 e 20 mostra que as respostas "muito frequente" diminuíram e as respostas "nunca" 
aumentaram. Já nos itens 16 e 31, as respostas "muito frequente" aumentaram e as respostas "nunca" também; porém no item 16 tais respostas aumentaram na mesma proporção. No item 31, as respostas "muito frequente" aumentaram duas vezes mais quando comparadas ao aumento das respostas "nunca". Nos itens 25 e 7, as respostas "muito frequente" aumentaram, porém no item 25 as respostas "nunca" se mantiveram estáveis, e no item 7 as respostas "nunca" diminuíram.

De forma geral, as pesquisadoras puderam observar boa receptividade dos alunos e professores quanto à intervenção proposta. Constatou-se também, por meio das observações das interações, que as crianças tornaram-se mais capazes de ajudar e consolar o colega, reconhecer e nomear sentimentos em si e nos outros, comunicar-se de modo mais assertivo, promover soluções alternativas para problemas reais e fictícios e diminuir a participação em conflitos interpessoais. As professoras das turmas que participaram do programa relataram melhoras significativas no convívio em sala de aula.

Os pais/responsáveis das crianças, os quais participaram das reuniões, também relataram mudanças comportamentais dos filhos no convívio familiar. Apesar da baixa frequência dos pais nas reuniões, aqueles que foram frequentes relataram estar mais aptos para lidar com seus filhos de forma menos agressiva e impaciente.

\section{DISCUSSÃO}

A diferença estatisticamente significativa entre $\mathrm{o}$ pré e o pós-teste, encontrada no item 7, que demonstra uma capacidade de negociação de forma assertiva, é corroborada pelos resultados encontrados por Borges e Marturano (2002). Estas autoras também encontraram indícios de um incremento das atitudes de negociação entre as crianças, o que, em ambos os casos, parece ser devido às habilidades promovidas pelo programa EPRP. A educação para a negociação, com valorização da assertividade na interação social, constitui uma capacidade importante para diminuição da violência, principalmente entre crianças, como apontam Loos e Zeller (2007). Além disso, a autonomia da criança deve ser buscada através de programas educacionais que lhes possibilitem perceber seus sentimentos e direitos bem como os dos outros (Shure \& Spivack, 1982).

O item 25 corrobora a ideia, trabalhada em praticamente todas as lições do programa, de que para perceber e ouvir o outro é preciso prestar atenção e seguir instruções. As consequências do desenvolvimento desta capacidade também podem ser verificadas pelas observações dos professores, que relatam melhora do convívio em sala de aula e da construção de um clima mais propício à aprendizagem das crianças, pois o professor interrompe menos vezes sua aula para intervir em conflitos ou conversas paralelas e se cansa menos ao final do dia, o que favorece também o desempenho escolar dos alunos (Elias \& Marturano, 2004).

No que se refere aos itens 6 e 20, o programa pareceu não ter contribuído para que a generalização de comportamentos pudesse ser concretizada. Durante as sessões da intervenção as crianças pareciam ter adquirido esta habilidade; contudo, como estavam em processo de aquisição de novos comportamentos, poderiam ainda não ter estendido esta capacidade para outros contextos. Não obstante, Baraldi e Silvares (2003) reforçam o fato de que o treinamento de habilidades sociais mostra-se benéfico para o aprimoramento das relações interpessoais, o que corrobora os resultados quantitativos e as observações do presente estudo.

Os itens 16 e 31 demonstram capacidade assertiva e maior iniciativa da criança. Ainda que estes itens não tenham sido trabalhados diretamente nas lições do livro, constatou-se que o EPRP contribuiu para que as crianças exibissem maior nível de adaptação psicossocial em termos comportamentais após a intervenção, o que concorda com os resultados encontrados por Elias, Marturano (2004), Shure e Spivack (1982).

Além disso, os dados das observações realizadas pelas pesquisadoras e pelos professores são concordantes com os resultados de Borges e Marturano (2009). A intervenção dirigiu-se a um grupo de crianças já integradas desde o início do ano letivo, o que pode ser considerado como um facilitador. Em situações de conflito, as autoras também ressaltam que as crianças se ajudavam mutuamente, dispensando a intervenção de um adulto, o que afetava positivamente os pares.

Borges e Marturano (2009) salientam, ainda, que as crianças participantes de sua pesquisa passaram a pensar em mais soluções para conflitos interpessoais, eliminando as respostas agressivas, e foram mais capazes de resolver um conflito de maneira autônoma e de enfrentar um problema de forma mais saudável após a intervenção com o programa EPRP, observações que vão ao encontro dos resultados do presente estudo.

Apesar de o foco de alguns programas preventivos na escola ser a própria criança, a literatura aponta que não se podem cogitar mudanças de comportamento infantil sem focalizar, concomitantemente, os pais (Baraldi \& Silvares, 2003; Guzzo, 2007). Desse modo, optou-se pelas reuniões de sensibilização e conscientização, com o intuito de propiciar um momento de reflexão sobre estratégias educativas para crianças. Embora a frequência destes pais às reuniões tenha ficado abaixo do esperado, os 
responsáveis que participaram das reuniões relataram grande satisfação com a oportunidade de discutir sobre a educação de seus filhos, o que vai ao encontro dos resultados encontrados por Webster-Stratton, Reid e Hammond (2004).

Diversos estudos que utilizaram o programa EPRP como foco de sua intervenção (Shure \& Spivack, 1982; Borges \& Marturano, 2002; Elias \& Marturano, 2004; Borges \& Marturano, 2009) obtiveram resultados que apontaram para a eficácia do programa no que diz respeito ao aprimoramento e desenvolvimento das habilidades de resolução de problemas interpessoais e à minimização de problemas de comportamento. De modo convergente, o estudo aqui em questão também encontrou resultados satisfatórios para as crianças participantes, considerando-se, de forma complementar, as observações contextuais realizadas pelas pesquisadoras e professoras e o relato dos pais, os quais indicam uma evolução significativa no desenvolvimento sociocognitivo das crianças.

\section{CONSIDERAÇÕES FINAIS}

Ressalta-se a relevância de se promoverem as habilidades infantis de resolução de problemas interpessoais no contexto escolar. Os resultados reportados evidenciaram incrementos comportamentais nos itens relativos a assertividade, civilidade, responsabilidade e expressão de sentimento positivo. Essa evolução concorda com os dados observados, evidenciando aumento das habilidades prévias e habilidades para resolução de conflitos. No trabalho concomitante realizado com os responsáveis e professoras, observou-se maior sensibilização destes quanto às suas estratégias educativas e manejo de comportamentos indisciplinados; além disso, eles se mostraram mais abertos às intervenções da psicologia escolar, sobretudo no que tange a estratégias preventivas. Programas promotores de competências socioemocionais infantis são de grande valia para favorecer o relacionamento interpessoal, pois a aprendizagem de comportamentos e modos de pensar na infância produz impacto na trajetória da vida adulta. Nesta perspectiva, as habilidades de resolução de problemas interpessoais constituem um fator de proteção para um desenvolvimento infantil saudável, já que intervenções que proporcionam o aprimoramento dessas habilidades contribuem para que a criança aprenda a negociar problemas inerentes à vida e, consequentemente, ela tenda a tornar-se um ser mais ativo e autônomo, capaz de lidar de maneira independente e criativa com seus problemas e de avaliar possíveis soluções e consequências. É importante destacar aqui a importância de envolver professores em trabalhos desta natureza, uma vez que eles estão diariamente em condições propícias para manejar problemas interpessoais e incentivar a própria criança a resolver problemas no contexto de sala de aula. Para isso se faz necessário promover programas permanentes de capacitação e educação. Os professores são os principais agentes da comunidade escolar e são fundamentais tanto para o desenvolvimento acadêmico quanto para o desenvolvimento socioemocional das crianças.

Cabe destacar algumas limitações do presente estudo, entre elas, o instrumento escolhido para mensuração das habilidades de resolução de problemas interpessoais nas crianças participantes. $\mathrm{O}$ SSRS-BR avalia diferentes categorias das habilidades sociais, contudo não inclui questões específicas referentes às habilidades de resolução de conflitos. Como a intervenção realizada focalizou essas habilidades, vários aspectos trabalhados durante o desenvolvimento do programa não puderam ser avaliados pelo instrumento. Além disso, o SSRS-BR foi validado para crianças de sete anos, sendo que, durante a pré e pós-avaliação alguns participantes ainda tinham apenas 6 anos. Dada a relevância do tema para a adaptação e saúde psicossocial infantil, sugere-se a realização de estudos que contemplem amostras mais abrangentes, instrumentos e recursos de avaliação diferenciados, bem como com trabalhos mais sistemáticos junto aos pais e professores.

\section{REFERÊNCIAS}

Anderson, R. J., Goddard, L., \& Powell, J. H. (2009). Social problem-solving processes and mood in college students: an examination of self-report and performance-based approaches. Cognitive Therapy Research, 33(2), 175186.

Bandeira, M., Del Prette, Z. A. P., Del Prette, A., \& Magalhães, T. (2009). Escala de habilidades sociais de estudantes do ensino fundamental (SSRS-BR). Psicologia: Teoria e Pesquisa, 2(2), 271-282.

Baraldi, D. M., \& Silvares, E. F. M. (2003). Treino de habilidades sociais em grupo com crianças agressivas, associado à orientação dos pais: análise empírica de uma proposta de atendimento. In A. Del Prette \& Z. A. P. Del Prette (Orgs.). Habilidades sociais, desenvolvimento $e$ aprendizagem (pp. 235-258). Campinas, SP: Alínea.

Bolsoni-Silva, A. T., Del Prette, Z. A. P., Del Prette, G., Montagner, A. R., Bandeira, M., \& Del Prette, A. (2006). A área das habilidades sociais no Brasil: uma análise dos estudos publicados em periódicos. In M. Bandeira, Z. A. P. Del Prette \& A. Del Prette (Orgs.). Estudos sobre as habilidades sociais e 
relacionamento interpessoal (pp. 1-45). São Paulo: Casa do Psicólogo.

Borges, D. S. C., \& Marturano, E. M. (2002). Desenvolvendo habilidades de solução de problemas interpessoais no ensino fundamental. Paidéia (Ribeirão Preto), 12(24), 185- 193.

Borges, D. S. C., \& Marturano, E. M. (2009). Aprendendo a gerenciar conflitos: um programa de intervenção para a $1^{\mathrm{a}}$ série do ensino fundamental. Paidéia (Ribeirão Preto), 19(42), 17-26.

Chrispino, A. (2007). Gestão do conflito escolar: da classificação dos conflitos aos modelos de mediação. Ensaio: avaliação de políticas públicas em educação, 15(54), 11-28.

Del Prette, A., \& Del Prette, Z. A. P. (2003). Aprendizagem socioemocional na infância e prevenção da violência: questões conceituais e metodologia da intervenção. In A. Del Prette \& Z. A. P. Del Prette (Orgs.). Habilidades sociais, desenvolvimento e aprendizagem (pp. 83-127). Campinas, SP: Alínea.

Del Prette, Z. A. P., \& Del Prette, A. (2005). Psicologia das habilidades sociais na infância: teoria e prática. Petrópolis, SP: Vozes.

Dessen, M. A., \& Polonia, A. C. (2007). A família e a escola como contextos de desenvolvimento humano. Paidéia (Ribeirão Preto), 17(36), 21-32.

Durlak, J. A., \& Wells, A. M. (1997). Primary prevention mental health programs for children and adolescents: a meta-analytic review. American Journal of Community Psychology, 25(2), $115-152$.

Elias, L. C. S., \& Marturano, E. M. (2004). Habilidades de solução de problemas interpessoais e a prevenção dos problemas de comportamento em escolares. In: E. M. Marturano, M. B. M. Linhares \& S. R. Loureiro (Orgs.). Vulnerabilidade e proteção: indicadores na trajetória de desenvolvimento do escolar (pp. 196-215). São Paulo: Casa do Psicólogo.

Elias, L. C. S., Marturano, E. M, Motta, A. M. A., \& Giurlani, A. G. (2003). Treating boys with low school achievement and behavior problems: comparison of two kinds of intervention. Psychological Reports, 92(1), 105-116.

Guzzo, R. S. L. (Org.). (2007). Desenvolvimento infantil: família, risco e proteção. Campinas, SP: Alínea.

Kazdin, A. E., Siegel, T. C., \& Bass, D. (1992). Cognitive problemsolving skills training and parent management training in the treatment of antisocial behavior in children. Journal of Consulting and Clinical Psychology, 60(5), 733-747.

Leme, M. I. S. (2004). Resolução de conflitos interpessoais: interações entre cognição e afetividade na cultura. Psicologia: Reflexão e Crítica, 17(3), 367-380.

Levin, J. (1987). Estatística aplicada às ciências humanas (2a ed.). São Paulo: Harbra.

Loos, H., \& Zeller, T. J. V. (2007). Aprendendo a "brigar melhor": administração de conflitos sem violência na escola. Interação em Psicologia, 11(2), 281-289.

López, M. (2008). La integración de las habilidades sociales en la escuela como estrategia para la salud emocional. Psicología sin
Fronteras: Revista Electrónica de Intervención Psicosocial y Psicología Comunitária, 3(1), 16-19. Recuperado em 10 de agosto, 2008 de http://www.psicologossinfronteras.net/Base/Revista/3_1_Febrer o_2008_lopez.pdf

Merrel, K. W., Buchanan, R., \& Tran, O. K. (2006). Relational aggression in children and adolescents: a review with implications for school settings. Psychology in the Schools, 43(3), 345-360.

Polletto, M., \& Koller, S. H. (2006). Resiliência: uma perspectiva conceitual e histórica. $\quad$ Em D. D. Dell' Aglio, S. H. Koller \& M. A. M. Yunes (Orgs.). Resiliência e psicologia positiva: interfaces do risco à proteção (pp. 18-44). São Paulo: Casa do Psicólogo.

Rodrigues, M. C. (2005). Prevenção na escola: um enfoque cognitivo-social. In M. M. P. E. Mota (Org.). Psicologia: interfaces com a educação e a saúde (pp. 11-30). Juiz de Fora: Editora UFJF.

Shure, M. B. \& Healey, K. N. (1993, agosto). Interpersonal problem solving and prevention in urban school children. Trabalho apresentado na Reunião Annual (Annual Meeting) da American Psychological Association, Toronto, Canadá.

Shure, M. B. (2006). Eu posso resolver problemas. Educação infantil e ensino fundamental: um programa de solução cognitiva para problemas interpessoais. (E. M. Marturano, A. M. A. Motta, L. C. S. Elias, Trad.). Petrópolis: Vozes (Original publicado em 1992).

Shure, M. B., \& Spivack, G. (1982). Interpersonal problem-solving in young children: a cognitive approach to prevention. American Journal of Community Psychology, 10(3), 341-356.

Vasconcellos, S. J. L., Picon, P., Prochnow, L. P., \& Gauer, G. J. C. (2006) O processamento das informações sociais em crianças e adolescentes. Estudos de Psicologia (Natal), 11(3), 275-279.

Webster-Stratton, C., Reid, M. J., \& Hammond, M. (2001). Preventing conduct problems, promoting social competence: a parent and teacher training partnership in head start. Journal of Clinical Child Psychology, 30(3), 283-302.

Webster-Stratton, C., Reid, M. J., \& Hammond, M. (2004). Treating children with early-onset conduct problems: intervention outcomes for parent, child, and teacher training. Journal of Clinical Child and Adolescent Psychology, 33(1), $105-124$.

World Health Organization (1999). Who information series on school health. Document Six. Geneva: Author.

Recebido em 16/10/2009 Aceito em 28/09/2010
Endereço para correspondência:

Marisa Cosenza Rodrigues. Praça Jarbas de Lery Santos, 37/103 B, São Mateus, CEP 36016-

390, Juiz de Fora-MG, Brasil. E-mail: rodriguesma@terra.com.br. 